\title{
FAMILY INTERVENTIONS TO DEAL WITH PSYCHO SOCIAL PROBLEMS OF CARETAKERS OF PERSONS LIVING WITH CANCER - CASE STUDY
}

\author{
Shwetha Rasquinha $1 \bowtie(D$, Dr Rameela Shekhar $2 \square$ \\ ${ }^{1}$ Asistance Professor, St Aloysius College (Autonomous) Mangalore, India \\ ${ }^{2}$ Professor (Rtd), Mental Health Professional, Manashanthi, Mangalore, India
}

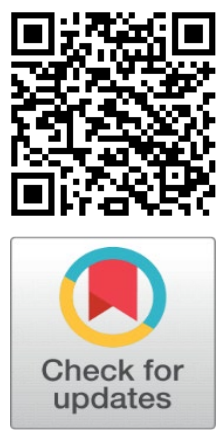

Received 2 September 2021

Accepted 14 September2021

Published 30 September2021

\section{CorrespondingAuthor}

Shwetha Rasquinha,

Shwetha_rasquinha@staloysius.edu. in

\section{DOI}

10.29121/granthaalayah.v9.i9.2021. 4256

Funding: This research received no specific grant from any funding agency in the public, commercial, or not-for-profit sectors.

Copyright: (C) 2021 The Author(s). This is an open access article distributed under the terms of the Creative Commons Attribution License, which permits unrestricted use, distribution, and reproduction in any medium, provided the original author and source are credited.

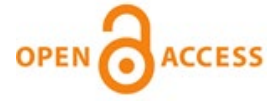

\section{ABSTRACT}

Family has a central role at the time of crisis. When an individual suffers with terminal illness like Cancer it definitely becomes more supportive. But in a crisisful situation like such, the family requires supportive interventions. This article presents a case study of primary caretaker of a cancer patient who undergoes severe psycho social challenges. Aim of this paper is to highlight the need and effectiveness of family intervention by Medical Social Worker through a case study. Psycho education to family, team work, utilizing the resources has shown remarkable results in reducing the psycho social problems of caretaker. Family environment plays a very significant role in psycho social support of its members. Positive environment and family socialization experiences enhances one's ability to cope with stress and anxiety. Hence family interventions for caretakers of persons living with cancer can support both care givers and patients. Multidisciplinary approach in cancer care is the need of the hour. It can build a proper support mechanism for the person suffering from cancer and his family. The most important implication of the current study is the unveiling of the need for Medical Social Workers in oncology settings and the interventions they can deliver. A professionally trained medical Social Worker, equipped with psycho social skills to work with caretakers, patients and their families can be a effective oncology Social Worker.

Keywords: Cancer, Caretaker, Family Interventions, Oncology, Medical Social Worker

\section{INTRODUCTION}

In India family is considered as a primary unit. Most terminally ill patients are cared in their own homes or in the hospitals by family and friends. Generally, the family provides the context to the patient to experience his /her diagnosis and prognosis but it changes the family forever. Diagnosis of Cancer to a family member may be most upsetting and dreaded event in a person's life; especially when the patient is a spouse, child, parent, sibling etc. Fear of losing loved one, caring for the person with Cancer, other responsibilities usually falls on the shoulders of immediate family member and for this family member playing multiple tasks may be over burdensome and lead to feeling of frustration and resentment. In the recent past, focus of Cancer treatment is extended to psychosocial treatment of whole family. Indian families with strong family ties should be the main unit of therapeutic intervention. Medical Social Worker has to use this strong family cohesiveness to implement the family therapy and make the family understand how they as a whole can be engaged in ensuring the Quality of Life of both person with Cancer and the caretaker. 
Western literature shows the significance of family interventions for caretakers of cancer patients. Wellish (1983) developed family therapy model for Cancer care and he proposed home visits to intervene the families. Family therapist should be ready to visit the family and they will be significantly benefitted by the therapists intervention. Effectiveness of case management programmes for families of chronically ill was determined. Hudson et al. (2009) suggested individual specific intervention to each caregiver along with generic interventions. Complications of each caregiver will vary based on numerous factors.

Hannon et al. (2012) identified family meetings as tool for sharing and obtaining information in palliative care as these meetings can address the initial concerns of the family members. One of the most potent factors in helping an individual to deal with stressful life conditions and events is social support. Social support is believed to reduce stress in three important ways (Coyne et al. (1981); Wills (1984). First family members, friends and acquaintances can provide direct material support in the form of physical resources ( e.g., lending money, taking care of children.) second, members of ones social network can provide informational support by suggesting alternative actions that may help to solve the stress producing problem. These suggestions may help the individual to look at his or her problem in a new way and thus help to solve it or minimize its impact. Third, those in the social network can provide emotional support through reassurance. These supportive individuals can provide nurturance, acceptance and love. These types of support have found to be important in helping an individual to cope with the demands of serious illness (Wortman and Schetter (1987)). It is evident from the reviewed literature that there is ample scope for psycho social interventions for caretakers of cancer patients. Each study has presented ideas on techniques or interventions to address caretaker's burden, stress and other needs. On the other hand much less attention has been given to research and building literature on various aspects of Indian family caretakers and interventions for them. Need of family interventions for both patient and caregiver were pointed by Padmaja et al. (2016). They suggested to include informational and emotional support to help both patients and their caretakers to accept the situation and live in reality. They strongly proposed research to explore such unique interventions. Since Cancer is a family illness, working with families in an effective way is the need of the hour.

Considering the need for such studies in Indian context this paper becomes relevant as it shows that structured family interventions can be of help to the caretakers to manage the challenges of caretaking

\section{METHODOLOGY}

A case study research design is used in this paper to present the experience of family caretaker and the outcome of family intervention given by Medical Social Worker. Face to face interview with the caretaker and family members was used to assess the experience and the needs of the caretaker. Becks Depression Inventory instrument was used to examine the depressive symptoms. After assessing the needs of the client, tailor made family intervention was given for a period of four months. Post intervention assessment was done after 4 months of intervention. Researcher being a trained professional Medical Social Worker has given the interventions in this case. 


\section{CASE ILLUSTRATION}

Patient $\mathrm{X}$ is 43 year old female residing in a village $60 \mathrm{kms}$ away from city of Mangalore. She is married and mother of two young children of 12 and 14 years old respectively. She worked as a domestic worker and her husband a driver. Their economic condition is poor as the income they get from their occupation is meager. For the complaints of breast pain and discomfort, fatigue and constant cough she was referred to a hospital in Mangalore city by a local doctor of her village. After clinical examinations she was diagnosed with breast cancer of advance stage.

\section{DETAILS OF CARETAKER}

Primary caretaker for patient $\mathrm{X}$ was her husband $\mathrm{Mr} \mathrm{Y}$ aged 50 years. He certainly had to balance the major roles of being a breadwinner, caretaker for his wife and father for two children. During the study assessment he reported a very poor quality of life and it is estimated by the researcher that he had been going through this before his wife was diagnosed with cancer because his wife due to symptoms of cancer was depending on her husband to a large extent.

\subsection{SUMMARY OF PSYCHO SOCIAL ASSESSMENT OF CARETAKER}

Caretaker Mr Y is unable to be regular for work as his wife was hospitalized in the city far away from their village. Daily commuting to hospital and attending to her needs left no time to go for his work. This has affected his income. He has a debt of Rs 50,000 which is taken from private money lenders and he is increasingly worried about repaying the debt. Cost of treatment (both direct and indirect cost) was increasing day by day and he has mortgaged their gold to get money. Knowing the financial condition of the family Mrs X (patient) has decided to delay or discontinue the treatment. Mr Y (caretaker) is in deep guilt feelings due to his helplessness to agree with wife's decision.

Caretakers psychological condition was assessed using Beck's Depression Inventory. He verbalized being discouraged about the future and being a failure as a husband and parent. Feelings of guilt, disappointment, irritability were observed. His ability level to take decisions, sleep, work had decreased. Overall his level of depression was between 31-40 indicating severe depression.

Being a caretaker had changed social relationship of Mr Y. Being at hospital and also managing the children and household chores had restricted his social life and leisure time. He was dissatisfied with the ability to perform the activities of daily activities. Since he had to stay at hospital with his ailing wife, he was able to bring his aged mother to be with his children. He was not open to reveal his wife's health condition to anyone in the family as he thought that he will be showing his helplessness to his family.

\section{COURSE OF FAMILY INTERVENTION}

Family interventions by professionals can develop the caretakers capacity to handle the situation. The goal of providing family support is to reduce the distress of caretakers, however it will ensure the Quality of Life of both caretaker and patient. Therapeutic relationship is vital to further interventions. Such relationship between the therapist and caretaker will ensure free flow of communication, wherein caretaker can genuinely share their apprehensions, difficulties, feelings etc. 
Therapist at this stage is expected to express his concern, warmth, and respect for the caretaker. This will create a space for the caretaker to involve his/her whole family in family interventions. In order to explore family support for the caretaker, researcher had a discussion with the caretaker regarding the need for family intervention and possibilities for support from family Caretaker and therapist planned as to how and where Medical Social Worker should meet the family members. In this case session, principles of self determination was followed by the researcher and with the consent of the caretaker a meeting of immediate family members was arranged at Mr Y's house. Home visit being a predominant tool of social work intervention was used in this situation to meet all family members from whom the necessary support could be obtained.

During the first session family psycho education was given in order to understand the condition of the patient, treatment, prognosis and the care required. In this strategy it is very important for Social Worker to have a thorough discussion with the oncologist and nurses.

Taking into account the binding of Indian families, family support to the client was planned. Family members were encouraged to share their concerns and challenges. As the caretaker doesn't have enough people to manage routine work, researcher along with caretaker explored possibilities of taking help of extended family.

Reframing technique of family intervention was used to help the family and caretaker to see this problem from a challenging and positive perspective. They were given space to ventilate negative feelings, fears of anticipated death and accept the situation as it is. Resources to meet the financial needs of the family were planned. Caretaker with the help of the researcher decided to apply for a state government scheme for health care and few Non Governmental organisations for help in cash or kind. Volunteers were also arranged to donate blood for further treatment.

Five family members were present during the home visit and they were asked to share the ways in which they could assist the caretaker and his dependants. They collectively decided that some would look after the children, some accompany Mrs $\mathrm{X}$ in the hospital so to give some relief to Mr Y. Family members were told that the researcher will keep follow up to ensure that they extend possible help to Mr Y. This kind of family intervention was done twice a month together with majority members who were present for the first session and others were followed up individually. Telephonic interventions were done for follow up and other necessary interventions were done through personal visits.

Along with family intervention individual sessions were held for caretaker giving him scope to ventilate and discuss his anxieties.

\section{OUTCOME OF INTERVENTION}

After a month of intervention $\mathrm{Mr}$ Y's scores on BDI showed marked improvement indicating reduction in symptoms of depression. His ability to work and take a few decisions improved. Researcher continued to be a mediator between the client and providers of financial support which reduced his financial burden on direct and indirect cost of treatment to some extent. It was found that there was constant decline in feelings of guilt and irritability. He maintained this improvement over the period of three months. However Mrs X's prognosis was poor and her health deteriorated further. But the social support for the client from his extended family was satisfactory because of which he managed to remain stable. When the researcher observed sustained changes in the family Medical Social Worker 
terminated the interventions. Professional Social work intervention support from family, utilizing the resources for tangible support helped the caretaker to reduce his distress and cope with the situation.

\section{DISCUSSION}

Medical advances have increased the chances of extending the life of a person with cancer. Hence caretakers need to be prepared for physical, emotional and social consequences of the illness for extended period (Bucher and Peter. (2011). Caretakers play a vital role in assisting the person with cancer. Impact of caretaking can be stressful and can also give the sense of satisfaction. Negative effects could be physical and psychological distress, financial and employment related hardships which can have long term consequences. Multidisciplinary approach in cancer care is the need of the hour. It can build a proper support mechanism for the person suffering from cancer and his family. The most important implication of the current study is the unveiling of the need for medical Social Workers in Oncology settings and the interventions they can deliver. However, it is important that medical Social Worker follows the principles of Social Work while working with the caretakers and families of terminally ill patients. To substantiate, while working with the emotions of life and death, controlled emotional involvement is a pre requisite to be free from professional burn out. It is necessary to accept the cultural, religious and ethnic diversities of each caretaker and integrate the services to their beliefs. Failure to maintain confidentiality can damage the warm relationship between the caretaker and Social Worker. Being non judgmental and accepting the caretaker as he/she are the important principles that need to be followed.

\section{CONCLUSION AND RECOMMENDATIONS}

In India, family caretakers play very noteworthy role in cancer care. Caretaking is physically, psychologically and socially very challenging, hence helping a caretaker to be effective should be the part of comprehensive cancer care.

Findings of the paper highlight the need to give attention to issues of primary caretakers. Family interevention has proved to be effective in this context despite the poor prognosis of the patient. Hence the profession of Social Work should advocate to develop standardized care for caretakers of persons with cancer through a professional oncology Social Worker in every oncology setting. Professional medical Social Worker who works in oncology settings need competency and knowledge on structured interventions for caretakers. Lack of adequate literature in this is also the reason contributing to this loophole. Research to measure effectiveness of Social Work intervention is still in its initial stage of development in India. This paper is a small step, but provides scope for further research in future particularly in Indian context. 


\section{REFERENCES}

Bucher, Julia, A., Houts, S, Peter. (2011).Complete guide to Family Caregiving. American Cancer society, America.

Coyne, J,C., Aldwin, C., Lazarus, R, S. (1981). Depression and Coping in Stressful Episodes. Journal of Abnormal Psychology .90; 439-447. Retrieved from https://doi.org/10.1037/0021-843X.90.5.439

Hannon, B., O'Reilly, V., Bennett K., Breen K., Lawlor P.G. (2012). Meeting The Family: Measuring Effectiveness of Family Meetings in a Specialist Inpatient Palliative Care Unit. Palliative Support Care. 10(1);43-9. Retrieved from https://doi.org/10.1017/S1478951511000575

Hudson, P., Thomas, T., Quinn K., Aranda, S. (2009). Family Meetings in Palliative Care: are they Effective? Palliative Medicine. 23(2);150-7. Retrieved from https://doi.org/10.1177/0269216308099960

Padmaja Gadiraju, Chhakchhuak Vanlalhruaii, Suvashisa Rana, Durgesh Nandinee, Meena Hariharan (2016). Caregivers' Depression, Anxiety, Distress, and Somatization as Predictors of Identical Symptoms in Cancer Patients. Journal Cancer Research and Therapeutic. 12 ( 1) : 53-57 Retrieved from https://doi.org/10.4103/0973-1482.146088

Wellish, D, K. (1983). Family Therapy with Cancer Patients: A Model. In L.R Walberg and M C Aronson (Eds) Group and Family Therapy New York: Brunner/Mazel 342-60.

Wills, T,A. (1984). Supportive Functions of Interpersonal Relationship- Social Support and Health. New York : Academic Press. Retrieved from https://psycnet.apa.org/record/1985-97489-004

Wortman, C,B., Dunkel, Schetter, C. (1987). Conceptual and Methodological Issues in the Study of Social Support. In A. Baum and J.E. Singer (Eds) Handbook of Psychology and Health. Hillsdale, NJ: Erlbaum 24-60 